\title{
A BIBLIOTECA PÚBLICA DE CAMPO GRANDE NOS ANOS 1930 PELAS PÁGINAS DA REVISTA FOLHA DA SERRA
}

\author{
Eglem de Oliveira Passone Rodrigues ${ }^{1}$ \\ Kênia Hilda Moreira²
}

\section{RESUMO}

Objetiva-se analisar a campanha de criação, implantação e funcionamento da Biblioteca Pública de Campo Grande, ao sul de Mato Grosso, na década de 1930, propagadas nas páginas da Revista Folha da Serra (RFS, 1931-1940). Questiona-se a relação entre a RFS e o surgimento da Sociedade da Biblioteca Pública de Campo Grande, organização criadora e mantenedora da Biblioteca em questão. Com referencial teórico-metodológico ancorado na Nova História Cultural, a análise compreende o impresso como importante fonte de pesquisa para a história da educação, numa perspectiva de educação para além dos muros da escola (CHARTIER, 1990; CATANI; BASTOS, 2002; BICCAS, 2008). Conclui-se que a Biblioteca Pública implantada pela RFS em Campo Grande na década de 1930, com seus eventos, concursos e debates influenciou novos hábitos, comportamentos e saberes, contribuindo para a formação e ampliação de leitores na região, expandindo, consequentemente o público potencial da RFS.

Palavras-chave: história da educação, Biblioteca Pública, imprensa.

${ }^{1}$ Universidade Federal da Grande Dourados (UFGD), Dourados/MS, Brasil.

${ }^{2}$ Universidade Federal da Grande Dourados (UFGD), Dourados/MS, Brasil. 


\title{
LA BIBLIOTECA PÚBLICA DE CAMPO GRANDE EN LOS AÑOS 1930 POR LAS PÁGINAS DE LA REVISTA FOLHA DA SERRA
}

\section{RESUMEN}

Se pretende analizar la campaña de creación, implantación y funcionamiento de la Biblioteca Pública de Campo Grande, al sur de Mato Grosso, en la década de 1930, propagadas en las páginas de la Revista Folha da Serra (RFS, 1931-1940). Se cuestiona la relación entre la RFS y el surgimiento de la Sociedad de la Biblioteca Pública de Campo Grande, organización creadora y mantenedora de la Biblioteca en cuestión. Con el referencial teórico-metodológico anclado en la Nueva Historia Cultural, el análisis comprende el impreso como importante fuente de investigación para la historia de la educación, en una perspectiva de educación más allá de los muros de la escuela (CHARTIER, 1990; CATANI; BASTOS, 2002; BICCAS, 2008). Se concluye que la Biblioteca Pública implantada por la RFS en Campo Grande en la década de 1930, con sus eventos, concursos y debates influenció nuevos hábitos, comportamientos y saberes, contribuyendo a la formación y ampliación de lectores en la región, expandiendo, consecuentemente el público potencial de la RFS.

Palabras clave: historia de la educación, Biblioteca Pública, prensa.

\section{THE PUBLIC LIBRARY OF BIG FIELD IN THE YEARS 1930 BY THE PAGES OF THE MAGAZINE FOLHA DA SERRA}

\begin{abstract}
The objective of this research is to analyze the campaign for the creation, implantation and operation of the Campo Grande Public Library, south of Mato Grosso, in the 1930s, propagated in the pages of Revista Folha da Serra (RFS, 1931-1940). The relationship between RFS and the emergence of the Campo Grande Public Library Society, the creator and maintainer of the Library in question, is questioned. With a theoretical-methodological reference anchored in the New Cultural History, the analysis includes the press as an important source of research for the history of education, in an educational perspective beyond the walls of the school (CHARTIER, 1990; CATANI; BASTOS, 2002; BICCAS, 2008). It is concluded that the Public Library implemented by RFS in Campo Grande in the 1930s, with its events, contests and debates influenced new habits, behaviors and knowledge, contributing to the formation and expansion of readers in the region, thus expanding the potential audience of RFS.
\end{abstract}

Keywords: history of education, Public Library, press. 


\section{LA BIBLIOTHÈQUE PUBLIQUE DU GRAND CHAMP DANS LES ANNÉES 1930 PAR LES PAGES DU MAGAZINE FOLHA DA SERRA}

\section{RÉSUMÉ}

L'objectif de cette recherche est d'analyser la campagne pour la création, l'implantation et le fonctionnement de la bibliothèque publique de Campo Grande, au sud du Mato Grosso, dans les années 1930, diffusée dans les pages de Revista Folha da Serra (RFS, 1931-1940). La relation entre RFS et l'émergence de la bibliothèque publique de Campo Grande, créateur et mainteneur de la bibliothèque en question, est remise en question. Avec une référence théoricométhodologique ancrée dans la Nouvelle histoire culturelle, l'analyse inclut l'imprimé comme une source de recherche importante pour l'histoire de l'éducation, dans une perspective éducative audelà des murs de l'école (CHARTIER, 1990; CATANI; BASTOS, 2002; BICCAS, 2008). Il est conclu que la bibliothèque publique mise en place par RFS à Campo Grande dans les années 1930, avec ses événements, ses concours et ses débats, a influencé de nouvelles habitudes, comportements et connaissances, contribuant ainsi à la formation et à l'expansion des lecteurs dans la région, par conséquent le public potentiel de la RFS.

Mots-clés: histoire de l'éducation, Bibliothèque Publique, presse. 


\section{INTRODUÇÃO}

A tessitura do texto que ora apresentamos analisa os movimentos de criação, implantação e funcionamento da Biblioteca Pública de Campo Grande, na década de 1930, localizada no sul do antigo Mato Grosso3, tendo como fonte a Revista Mensal Ilustrada Folha da Serra (RFS). Questionamos a relação entre a RFS e o surgimento da Sociedade da Biblioteca Pública de Campo Grande, organização criadora e mantenedora da Biblioteca. De modo mais abrangente, indagamos a produção e circulação da Revista em Mato Grosso em meio a ações políticas que perpassaram o primeiro governo de Getúlio Vargas, propondo novos hábitos, saberes e valores, influenciando a formação de um novo cidadão, que atendesse à nova proposição de modernidade, em consonância com o governo vigente, criando, dentre outras práticas, a referida Biblioteca Pública e, dentre outras representações, a importância dessa instituição, incentivando o gosto pela leitura.

A Revista Folha da Serra foi um periódico de produção mensal de variedades, independente e por assinatura, produzida em Campo Grande pelo editor-proprietário Aguinaldo Trouy4, com circulação em todo o Estado, em especial na parte sul, entre 1931 a 1940. Uma das grandes marcas da RFS e motivo de orgulho estava ligada ao fato de o periódico ser ilustrado: "A única publicação ilustrada em Mato Grosso. Dedicada à propaganda do Estado” (RFS, n. 13, 14 e 15, out., nov. e dez. 1932, p. 15), contribuindo com a "farta colaboração literária e variada ilustração sobre o nosso município” (Id., p. 19)5.

\footnotetext{
3 Até 1977, a cidade de Campo Grande localizava-se ao sul de Mato Grosso. Com a divisão estadual ocorrida nesse ano, Campo Grande passa a ser capital de Mato Grosso do Sul.

4 Impressa pela Gráfica Aguinaldo Trouy \& Cia, portanto, o proprietário e editor da Revista também era proprietário da gráfica onde a revista era produzida e impressa. A redação responsável pelas publicações localizava-se na Rua João Pessoa, n. 864, na cidade de Campo Grande, Estado de Mato Grosso.

5 As buscas, a fim de proporcionar o levantamento da RFS, foram realizadas em Arquivos e Acervos. No Acervo professor José Pereira Lins, localizado na Biblioteca Central e no Centro de Documentação Regional (CDR) da UFGD; no Arquivo Histórico de Campo Grande (Arca); no Arquivo Público de Mato Grosso (APMT), em Cuiabá. Foram localizados 48 exemplares da RFS, a totalidade de números publicados.
} 
Ancorado no campo da História da Educação, na perspectiva da Nova História Cultural, a análise a que nos propomos enxerga a RFS como um gênero impresso específico denominado "revista de variedades"6. O interesse pelo impresso como fonte/objeto para a história da educação no Brasil, conforme Catani e Bastos (2002), ganha força a partir do final da década de 1980 e a proliferação e diversificação das pesquisas foram mais visíveis dos anos 1990 aos nossos dias7.

Consideramos como impressos os periódicos e as revistas que têm como objetivo informar e criar opinião, construindo espaços sociais coletivos. Um instrumento de comunicação social que faz parte da vida quotidiana dos cidadãos e desse modo, também espaço de presença de educação e seus problemas, além de permanente ação educativa (BICCAS, 2008). Nesse sentido, a possibilidade de escrever uma história da educação a partir da RFS considera a imprensa, de modo geral, como importante meio de transmissão de valores, crenças, hábitos e saberes, numa concepção de educação que vai além das paredes da escola, afinal, portadores da palavra escrita, os impressos "cimentam as sociabilidades e prescrevem os comportamentos, atravessam o foro privado e a praça pública, levam a crer, a fazer ou a imaginar" (CHARTIER, 1990, p. 138).

A fim de desdobrar a proposta aqui apresentada, o texto foi organizado em duas partes. Na primeira: A criação da Biblioteca Pública de Campo Grande,

\footnotetext{
${ }^{6}$ O termo "variedades" na história do periodismo significa, para além do que efetivamente diz (a variedade de assuntos), a amenidade dos conteúdos enfocados, o que significa uma diversificação não apenas nos impressos, mas nas práticas de leitura, e no público leitor. A esse respeito, conferir: Luca (2005); Chartier (1996); Batista; Galvão (1996), dentre outros.

7 Sobre a inserção do impresso como fonte de pesquisa histórica, entre as pesquisas internacionais destaca-se os trabalhos de Maurits de Vroede (1987), que investiga as revistas belgas dos séculos XIX e XX, Pierre Caspard (1988) que elenca revistas francesas do século XVIII a princípios do século XX, Giorgio Chiosso (1992), que destaca as revistas italianas da segunda metade do século XVIII e António Nóvoa (1994), que toma a imprensa de educação e ensino portuguesa, nos séculos XIX e XX e os recentes trabalhos do espanhol Fernández Díaz (2013) que apresenta a imprensa pedagógica como patrimônio histórico educativo. Denice Barbara Catani, Maria Helena Câmara Bastos, Marta Carvalho e seus orientandos respectivos impulsionaram os estudos em torno das revistas pedagógicas no Brasil. Pesquisas estas inseridas nas mudanças ancoradas nas inovações paradigmáticas a partir da década de 1970 que determinaram a transformação no modo de entender a história e desenvolver sua pesquisa científica, conduzida segundo princípios metodológicos profundamente renovados, a partir das contribuições da Nova História Cultural.
} 
indagamos sobre o público-alvo e os objetivos de criação e implantação da instituição. Na segunda: Funcionamento da Biblioteca Pública de Campo Grande, apresentamos um panorama administrativo e suas principais atividades durante os anos 1930, em busca de expor algumas práticas e representações da referida instituição a partir das páginas da RFS.

\section{A CRIAÇÃO DA BIBLIOTECA PÚBLICA DE CAMPO GRANDE}

Neste tópico, apresentamos as chamadas divulgadas na Revista Folha da Serra (RFS) em prol da criação, implantação e ampliação da Biblioteca Pública de Campo Grande, questionando o público-alvo e os objetivos da referida instituição nesse sertão do país, durante os anos 1930, cientes de que o impresso, aqui utilizado como fonte, obedeceu a categorias de pensamento e formas de apreensão do real que, ao representarem uma dada situação, expõem "vestígios ou indícios que permitem a reconstrução sempre submetida a controle", das realidades que os produzem (CHARTIER, 1990, p. 88).

No início dos anos 1930, Mato Grosso representava a parte do Brasil "sertanejo", "pobre analfabeto e inculto" (CHAUÍ, 2000, p. 67), em oposição ao Brasil "litorâneo", representado pela elite intelectual e burguesa. Inserido na parte sertaneja do Brasil, Mato Grosso era interpretado como lugar de atraso e selvageria, ao mesmo tempo em que representava "uma reserva de brasilidade" (GALETTI, 2000, p. 23). Nesse sentido, os olhos se voltam para esse sertão, com o objetivo de nacionalização e integração, na perspectiva da política varguista. Ao mesmo tempo, parcela da população mato-grossense objetivava corresponder à necessidade de modernização, espelhando-se nos grandes centros em busca da urbanização que passava, dentre outros aspectos, pela criação de instituições educativas, como a Biblioteca Pública em questão.

A primeira biblioteca aberta ao público no Brasil foi a Biblioteca 
Nacional, instalada com a vinda da Família Real em 1808, mas só disponível em 1824. De acordo com Cesarino (2006), a primeira biblioteca pública foi criada em Salvador, na Bahia, em 1811. Segundo Paiva (2008), até 1930 o país contava apenas com 27 bibliotecas públicas, concentradas, sobretudo, na região sudeste. Por outro lado, 83 bibliotecas populares, atendendo a públicos distintos, foram criadas por grupos como sindicatos, associações profissionais e religiosas, entre 1890 e 1930 (GOMES, 1983, p. 76 apud PAIVA, 2008, p. 27). A partir daí, esse tipo de instituição passou a se expandir pelo país, como sinônimo de progresso e modernidade, por meio da democratização do acesso à informação. É dentro desse movimento, acreditamos, que a Biblioteca Pública de Campo Grande foi criada.

O primeiro pronunciamento em prol da instalação de uma biblioteca para Campo Grande data de 1931, no primeiro número da Revista Folha da Serra, com o título Biblioteca de Campo Grande, o que evidencia certa junção de interesses entre a criação da Revista e a da Biblioteca. A matéria discorre sobre a necessidade de construção de uma biblioteca pública na cidade, aclamando ao "ilustre Dr. Interventor Municipal", Vespasiano Barbosa Martins, e aos "progressistas de Campo Grande", a favor da construção de uma biblioteca pública. $\mathrm{O}$ artigo registra um movimento a fim de despertar a população "progressista" da cidade, bem como a administração local, tendo em vista um lugar específico para as pessoas "letradas se instruírem" (RFS, n. 1, out. 1931, p. 4).

Para reforçar tal necessidade, cita o Gabinete Corumbaense de Leituras, na cidade de Corumbá8, lugar

\footnotetext{
${ }^{8}$ A comparação entre as cidades, prática constante na Revista, se justifica na tentativa de igualar Campo Grande a Corumbá, considerada cidade modelo, com maior projeção que Cuiabá capital de Mato Grosso, em alguns aspectos econômicos e culturais nesse período. Criada em 1778, elevada a Distrito em 1838 e a Município em 1850, Corumbá foi, durante a Guerra da Tríplice Aliança, palco de uma das principais batalhas, ocupada e destruída pelas tropas de Solano Lopez, em 1865. Após a guerra, o porto de Corumbá tornou-se o terceiro maior porto fluvial da América Latina até 1930. Até a década de 1950, os Rios Paraguai, Paraná e da Prata eram o único meio de comunicação da região até a chegada da Estrada de Ferro Noroeste do Brasil. Mais informações em Brito (2001), Queiroz (2004).
} 
[...] onde todas as noites se reúne o que de intelectual possui a linda 'Princesa do Paraguai'. Vem-se, ali, absortos na leitura de suas obras prediletas ou consultivas estudantes, senhorinhas e senhores, cavalheiros, enfim, representantes de todas as classes sociais, sob um ambiente seleto e instrutivo (RFS, n. 1, out. 1931, p. 4).

Sobre o público-alvo, o autor afirma que a criação de uma biblioteca em Campo Grande, "a exemplo" do "Gabinete Corumbaense de Leituras", beneficiaria a "todas as classes sociais", ao mesmo tempo em que seria um espaço reservado para as pessoas "letradas se instruírem". Em seguida, o autor sugere um valor a ser pago mensalmente, como forma de manutenção da Sociedade da Biblioteca de Campo Grande, o que nos leva a concluir que a biblioteca era pública, mas não gratuita.

Certo é, que para levar-se a termo esta organização, teremos que promover os meios para sua manutenção. Julgamos não ser esta a pior tarefa pois em sociedade, com a joia inicial de dez mil réis e mensalmente de três, seria o bastante para obter-se os recursos necessários ao desenvolvimento da Biblioteca. Estas cotas estando ao alcance de todas as bolsas, dará ensejo a se conseguir maior número de associados, o que devemos visar (RFS, n. 1, out. 1931, p. 4).

Os associados deveriam pagar uma mensalidade, além de doar uma cooperação inicial para o desenvolvimento da Biblioteca. A matéria esclarece que esses valores estão "ao alcance de todas as bolsas", no entanto, acreditamos que essa proposta não poderia incluir "todas as classes sociais" por dois fatores básicos: em 1931, nem todos sabiam ler e nem todos os bolsos seriam alcançados com o valor proposto. Parece haver, portanto, um público específico mirado pela Sociedade da Biblioteca Pública.

A prática de criação de associações e/ou sociedades, parece ter sido uma constante na cidade nesse contexto histórico, como afirma Oliva Enciso ao apresentar a Sociedade Miguel Couto dos amigos do estudante, criada em $1940^{9}$.

${ }_{9}$ Cf. Enciso (1986). 
Sobre as sociedades, ela afirma que

em Campo Grande, felizmente, há diversas: uma, cuidando dos doentes; outra, recolhendo os velhos desamparados; esta, trabalhando em benefício dos filhos dos leprosos; aquela, procurando proteger as mães e seus filhinhos pobres (RFS, n. 45, set. 1940, p. 11-12).

Assim como a Sociedade da Biblioteca de Campo Grande, a Sociedade Miguel Couto dos amigos do estudante, criada anos depois, prestava-se a auxiliar o poder público em suas funções de atender o bem-estar social, com ênfase na educação. Em termos de comparação, o valor cobrado pela Sociedade Miguel Couto dos amigos dos estudantes era de cinco mil reis mensais: "Leitor amigo reserve no mínimo, cinco mil réis mensais de vossa economia, para socorrermos o estudante pobre, que as vezes deixa de estudar por não ter um livro!" (RFS, n. 45, set. 1940, p. 12).

Em 1932, a instalação de uma biblioteca em Campo Grande é retomada como assunto na edição número 11 e 12 da RFS, com o artigo Biblioteca Pública de Campo Grande, indicando ser de autoria do corpo editorial da Revista. O artigo comunica que o redator da Folha da Serra, Sr. Dr. Peri Alves Campos, um "abalizado clínico nesta cidade, homem de letras", está organizando a fundação "desta louvável e útil instituição" que sanará uma "grande lacuna existente em nosso meio social" (RFS, ns. 11 e 12, ago. e set. 1932, p. 12). Encontramos aí o vínculo entre a RFS e a futura Biblioteca, igualmente uma justificativa para a criação da mesma: sanar uma lacuna da sociedade campo-grandense.

O referido artigo afirma que já existiu em Campo Grande uma "Biblioteca Pública ou coisa equivalente" e que os pertences foram "atirados em um depósito da Prefeitura Municipal, ficando assim o público progressista e amante das boas letras logrado de suas intenções”. Por fim, felicita Peri Campos e outros a tentarem novamente a instalação "deste imprescindível centro de culturas", que será a Biblioteca de Campo Grande (RFS, ns. 11 e 12, ago. e set. 1932, p. 12). 
Meses mais tarde, o artigo A instalação da Biblioteca de Campo Grande afirma que a instituição foi fundada e "será mantida pela sociedade do mesmo nome", ou seja, pela Sociedade da Biblioteca de Campo Grande, criada em 28 de novembro de 1932. A Biblioteca foi instalada no dia oito de janeiro de 1933, na Afonso Pena, principal avenida da cidade, com sessão inaugural e "elevado número de pessoas, entre as quais diversas representantes do belo sexo" (RFS, ns. 13, 14 e 15, out., nov. e dez. 1932, p. 3). Apesar de a solenidade de abertura da Biblioteca de Campo Grande ter contado com a presença do "belo sexo" - dentre as 30 pessoas presentes, sete eram mulheres ${ }^{10}$ - nenhuma é mencionada com cargo administrativo ou com oportunidade de fala na cerimônia de inauguração. No entanto, esta afirmação somada a de que, está entre os objetivos da Sociedade da Biblioteca de Campo Grande, "facilitar o estudo das ciências, letras e artes em geral e, de modo particular, das brasileiras" (RFS, n. 25, 1933, p. 14, grifo nosso), evidencia uma ênfase às leitoras, por parte dessa instituição.

Voltando a sessão inaugural, registra-se a presença do prefeito da cidade, Itrio Corrêa da Costa. Destaca-se a presença do diretor da RFS, Aguinaldo Trouy, além do presidente da Biblioteca e da Sociedade da Biblioteca de Campo Grande, Peri Alves Barros, que também é redator chefe da Revista, o que reforça o vínculo entre a Biblioteca e a RFS. Os oradores foram, Estácio Corrêa Trindade, que enfatizou que "as Bibliotecas Públicas [...] completam a escola”, e Manoel Garcia de Sousa, para quem "um povo só é forte e digno, quando educada, e instruída a massa humilde". $\mathrm{O}$ artigo de inauguração destaca o pronunciamento do prefeito que

\footnotetext{
${ }^{10}$ A solenidade contou com uma ata, a qual registraram 30 assinaturas dos presentes: "Joaquim Cesário da Silva, Itrio Corrêa da Costa, Dr. Peri Alves Campos, Manoel Garcia de Souza, Evangelina Vieira de Almeida, Nadir Velasco, Lenira Velasco, Mary Alves Campos, Maria Alves Corrêa de Campos, Lucina Prado de Albuquerque, Antonio Leite de Campos, Doutor Alcindo Moreira de Figueiredo, Caetanos Albuquerque, Estácio Corrêa Trindade, Timoteo Rostey, Carlos C. Cardososo, Cesar Teles, Carlos Viviam, pelo Colégio Oswaldo Cruz, Maria Ignez Alves de Campos, Benjamim Adese, Virgilio Corrêa, Aguinaldo Trouy, João C. Ribeiro, Alvaro Antunes, Orlando Araujo, Mariano Cebalho, Augusto Gonçalves Dias, E. Coutinho, Dr. Fernando Correa da Costa" (RFS, ns. 13, 14 e 15, out., nov. e dez. 1932, p. 3).
} 
[...] faz referências ao poder público municipal, que já concedeu uma subvenção à Escola Ativa desta cidade, para o funcionamento de aulas noturnas aos pobres, completando-se com essa medida o auxílio da instrução elementar e cultural ao povo, com as mesmas vantagens já concedidas a esta Biblioteca (RFS, ns. 13, 14 e 15, out., nov. e dez. 1932, p. 3). ${ }^{11}$

Tal referência confirma a participação do poder público na criação da Biblioteca Pública de Campo Grande, apesar da iniciativa particular, por parte da Sociedade da Biblioteca de Campo Grande, criada, pelos indícios disponíveis, por iniciativa do grupo dirigente da RFS, tratando-se de uma instituição pública, com subvenção municipal, de acesso não gratuito, restrito aos associados.

Em março de 1933, o artigo A arte e o ensino, de Lobivar de Matos ${ }^{12}$, retoma o assunto sobre a Biblioteca Pública de Campo Grande, para fazer uma análise aos esforços em torno da criação e utilização da instituição, tendo em vista o público a que ela se destina:

Falar sobre Arte em Campo Grande é ser ouvido só por alguns pássaros
que descansam à sombra da árvore - Esquecimento. Aqui tudo é
promessa. Todos os moços vão atrás do prazer que lhes promete uma
felicidade; todos os velhos vão atrás da política que lhes oferecem um
cargo público. Por enquanto a vida em Campo Grande é simplesmente
material. [...] Mesmo os que gostam da Arte, os seus admiradores, nada
podem fazer por ela. Exemplo vivo, ali está representado pela nossa
Biblioteca Pública, fundada, só Deus e o Dr. Peri sabem como. [...] E a

${ }^{11}$ A inauguração da Biblioteca Pública ocorreu em 1933, contudo o número da Revista indica 1932. Este aparente descompasso se justifica pelo atraso na publicação da edição referente aos números 13 (out.),14 (nov.) e 15 (dez.) do ano findo de 1932. Portanto, os respetivos números foram publicados apenas em janeiro de 1933, como explica o editorial "A Presente edição explicação necessária" (RFS, ns. 13, 14 e 15, out., nov. e dez. 1932, p. 3).

${ }^{12}$ Lobivar de Matos (1915-1947), importante figura sul-mato-grossense, destacou-se como poeta, jornalista e crítico literário. Lobivar brilhou em inúmeras páginas da Revista Folha da Serra (n. 5, fev. 1932; n. 16, jan. 1933; n. 18, mar. 1933; n. 23, ago. 1933; n. 24, set. 1933; n. 25, out. 1933; n. 26, nov. 1933; ns. 28 e 29, jan. e fev. 1934; n. 30, mar. 1934; n. 40, ago. 1936; n. 46, out. 1940), com seus poemas (dez), assinou também alguns artigos (dois), tomando parte na Revista como colaborador, mesmo após sua mudança de Corumbá para o Rio de Janeiro, de onde continuou a colaborar. Publicou ao longo de sua vida duas obras: Areôtorare: poemas boróros em 1935 (noticiado na RFS, ns.37 e 38, jan. e fev. 1935, p. 18) e Sarobá em 1936 (também foi noticiado na RFS, n. 40, ago. 1936, p. 100). Além de duas obras não publicadas: Cacos de vida, Contos e Rendas de interrogação. Suas obras, bem como sua biografia, vêm sendo alvo de estudos. Cf. Araujo (2009), dentre outros. 
Biblioteca está fundada ha quase dois meses. Hoje, podemos dizer, orgulhosos: Campo Grande, já possui uma casa de leituras, um gabinete de aprendizagens. Mas de que valeu esse esforço grandíloquo? (RFS, n. 18, mar. 1933, p. 6).

O artigo de Lobivar de Matos se diferencia dos discursos eloquentes e apaixonados que até então perpassaram as páginas da Revista, no que diz respeito à Biblioteca. $\mathrm{O}$ autor chama a atenção para o descaso por parte do seu público alvo, por um lado, os jovens, entregues aos prazeres da vida material, por outro, os "velhos", interessados em galgar espaços na vida política, em busca de "cargos públicos”, nem um, nem outro, interessado em frequentar o recém instalado “centro de culturas" denominado Biblioteca Pública de Campo Grande. O autor continua:

\footnotetext{
Para mim foi uma obra grandiosa e digna de aplausos sinceros. Para outros não sei se valeu alguma coisa, porque quando passamos por ela, à noite, vemo-la sempre com as suas portas abertas, como convidando o povo a entrar, e um profundo aborrecimento nos invade. Por que? Porque achamos poucas as pessoas que lá estão sentadas comendo o pão espiritual e bebendo a água pura e cristalina do saber. Que representam para Campo Grande os 500 leitores mensais de sua Biblioteca? Onde está a mocidade forte, a mocidade intelectual, a mocidade entusiasta, a mocidade moderna de Campo Grande? Onde? (RFS, n. 18, mar. 1933, p. 6).
}

Ao contrário do que parecia ser o cotidiano do "Gabinete Corumbaense de Leituras", na cidade de Corumbá, frequentado por "senhoritas e senhores" de “todas as classes sociais", como anunciado anteriormente, a Biblioteca de Campo Grande aparece, na análise de Lobivar de Matos, esvaziada de público em geral, em especial do público jovem, mesmo estando "de portas abertas" no período noturno, o que, teoricamente, deveria ser uma oportunidade para os que não dispusessem de tempo livre no período diurno.

Seguindo esse mesmo discurso de indignação pela escassez de interesse da população campo-grandense por essa instituição, o artigo Horror aos livros 
afirma que o número de associados a Biblioteca é reduzido, "insignificante até, e não condiz com o desenvolvimento de Campo Grande".

\begin{abstract}
Não é admissível que a nossa cidade, a primeira do Estado, a mais próxima dos grandes centros, excluindo Três Lagoas que longe está do nosso desenvolvimento, de à biblioteca um tão insignificante número de sócios (150, se muito), quando o seu número de habitantes é de 12.00o no perímetro urbano. [...] Quando me certifiquei da exatidão dos números tive certo descontentamento e vi, horrorizado, armaremse diante dos meus olhos estas palavras: 'A NOSSA GENTE TEM HORROR AOS LIVROS'! Infelizmente assim é (RFS, n. 25, out. 1933, p. 14, grifo no original).
\end{abstract}

Quais seriam as justificativas para que a população campo-grandense não se interessasse pela Biblioteca? $O$ autor apresenta alguns possíveis argumentos para as pessoas não se associarem à referida instituição, como a questão financeira, mas refuta esse argumento:

Crise monetária também não admito. Os cinemas estão sempre cheios e os cafés abarrotados. Ademais três mil réis por mês não é quantia que nos possa tornar mais pobres. E uma só coisa justificável nos salta à mente: 'horror aos livros!' [...] é essa mesma mocidade que traçará as nossas diretrizes de amanhã. E o 'amanhã' queremo-lo melhor do que o 'hoje'. Um pouco mais de amor aos livros que nos instruam. Para os que não dispõem de meios para adquiri-los em livrarias, aí está a biblioteca que só exige três mil réis por mês por quantos livros quiserem ler. Associem-se (RFS, n. 25, out. 1933, p. 14).

Tal afirmação soma-se aos discursos que apresentam a Biblioteca Pública como espaço de instrução para melhor usufruto da juventude. Um lugar criado para contribuir com o crescimento intelectual da cidade de Campo Grande. A RFS, como veículo de comunicação, serve-se de instrumento para propagar essas práticas e representações. No entanto, ao mesmo tempo em que a revista tem como objetivo incentivar a população a se associar a biblioteca, evidencia a dificuldade de aquisição de novos hábitos e valores por parte dos campograndenses, como o hábito de passar a frequentar esse novo ambiente, "seleto e 
instrutivo", conhecido como Biblioteca Pública.

A afirmação sobre o número de leitores (500, como mencionou Lobivar de Matos) e o número de sócios (150, se muito), nos levou a questionar sobre a população de Campo Grande. A Revista Folha da Serra informa que "pode-se calcular seguramente em 40.000 o número de habitantes deste município, 25.000 dos quais se encontram na cidade, sendo 12.000 no perímetro urbano e 13.00o nas zonas suburbana e rústica" (RFS, n. 23, ago. 1933, p. 63). A RFS também informa que o número de alunos matriculados em 1933 era de 2.580, sendo, 2.114 no curso primário, 272 no ginasial, 113 no normal e 81 no comercial (RFS, n. 23, ago. 1933, p. 68-69). Concluímos que o número de leitores da recémcriada Biblioteca Pública, na afirmação de Lobivar, representava 1/5 (um quinto) dos estudantes matriculados. Talvez esse baixo número se justifique em virtude da concentração de alunos no ensino primário, que representava mais de 80\% das matrículas. O que significa dizer, que se trata de crianças em processo de alfabetização e letramento, enquanto o público alvo da biblioteca parecia referirse a jovens e adultos/“velhos".

Entre as finalidades da Sociedade, segundo seu estatuto, está a de contribuir com a educação "moral e intelectual" da sociedade campo-grandense, pois a Biblioteca Pública criada por ela deveria trabalhar em parceria com as funções da escola, facilitando "o estudo das ciências, letras e artes", trabalhando "junto aos colegiais", promovendo eventos em prol do "nível cultural do povo" (RFS, n. 25, 1933, p. 14). Sobre os colegiais, constatamos que no início dos anos 1930, o ensino ginasial é oferecido na cidade de Campo Grande, com vistas a atender o sul do Estado, por duas instituições, sendo uma pública, o Ginásio Municipal (171 matriculados no curso), e uma privada, o Internato Osvaldo Cruz (101 matriculados), totalizando 272 matrículas. O ensino normal é ofertado no Colégio Nossa Senhora Auxiliadora (85) e na Escola Modelo e Normal (28), somando 113 matrículas. O Ensino Comercial é ofertado no Colégio Nossa Senhora Auxiliadora (67) e no Internato Osvaldo Cruz (14 matriculados), perfazendo 81 matrículas. Tais dados corroboram a hipótese de que era reduzido 
o número de jovens matriculados no ensino secundário em Campo Grande nesse período e, consequentemente, reduzido o público alvo da Biblioteca Pública.

A RFS foi, sem dúvida, uma grande aliada à campanha em prol da criação da Biblioteca Pública de Campo Grande, tendo em vista que, seu redator chefe desempenhou importante posição desde a idealização até a efetivação da Sociedade, tendo como principal instrumento a seu favor, a propagação da campanha pelas páginas da Revista. Ela disseminou discursos em prol da criação, implementação e manutenção da Biblioteca. Entretanto, é importante destacar que a RFS não fez campanha em prol da Biblioteca Pública de maneira isenta, interessada tão somente no bem maior da sociedade campo-grandense, uma vez que o mentor da Sociedade da Biblioteca Pública de Campo Grande, também redator chefe da RFS, era sabido que a Revista só teria sucesso em uma sociedade leitora, não apenas que soubesse, mas que gostasse de ler. De que adianta uma Revista se o povo não lê? Nesse sentido, não é ingênuo o incentivo investido nas páginas da RFS a favor da Biblioteca Pública de Campo Grande e da insistência pela valorização dos livros e do hábito da leitura, bem como a ênfase no público feminino, considerando que a revista de variedades seria do agrado do "belo sexo".

Nesse sentido, como evidenciou Faria Filho (2002, p. 134) ao tratar do poder do impresso, podemos afirmar que a RFS se utilizou de "estratégia de construção de consensos, de propaganda", promovendo "novas sensibilidades, maneiras e costumes" ao criar a Biblioteca Pública de Campo Grande, como uma importante "estratégia" educativa, na perspectiva analítica de Certeau (1994). Deste modo, o discurso criado pela Revista precisava valorizar a importância dessa instituição como um "imprescindível centro de culturas", uma "casa de leituras", um "gabinete de aprendizagens", que complementaria o papel da escola, tratando-se, de uma "louvável e útil instituição", "digna de aplausos sinceros". Para tanto, contou com a colaboração da população "progressista" da cidade e da administração local na produção de sensibilidades a favor da criação de uma Biblioteca Pública, destinada à mocidade intelectual e letrada de Campo 
Grande.

\section{FUNCIONAMENTO DA BIBLIOTECA PÚBLICA DE CAMPO GRANDE}

Três anos após a instalação da Biblioteca Pública de Campo Grande, o presidente da Sociedade da Biblioteca e redator chefe da RFS relembra como havia ocorrido a criação dessa instituição. Primeiro, criou-se a Sociedade. Com "intensa campanha jornalística logramos, auxiliados por amigos, a 28-11-32 em nosso consultório, fundar a Sociedade da Biblioteca de Campo Grande”; após dois meses, no dia oito de janeiro de 1933, "instalava a sua sede e franqueava-a ao público" com o título de "Biblioteca Pública”, o Estatuto e Regimento Interno da Sociedade, foi aprovado em 18 de julho de 1933 e "publicado pela 'Gazeta Oficial' de 5-10-33” (RFS, n. 40, ago. 1936, p. 82, grifo no original).

O quadro administrativo da Biblioteca é o mesmo que compõe a Sociedade da Biblioteca Pública de Campo Grande que a mantém. A presidência ficou a cargo do médico Peri Alves Barros, e a secretaria, de Joaquim Cesário da Silva. Não há uma lista com os nomes dos sócios da Biblioteca ou da Sociedade, contudo, há no Estatuto e Regimento Interno da Sociedade da Biblioteca de Campo Grande, distinções entre os associados, que se dividem em quatro categorias: efetivos, operários, beneméritos e correspondentes. No capítulo II do Estatuto: Dos sócios, seus deveres e direitos, para cada categoria existia um valor a ser pago correspondente à mensalidade, além de uma quantia chamada de “joia”, como já anunciado, referente à taxa inicial, paga por todos os novos sócios.

$\S 1^{\circ}$ - efetivos o que, domiciliados nesta cidade, contribuírem mensalmente com a quantia de $3 \$ 000$ e pagarem a joia de $10 \$ 000$;

$\S 2^{\circ}$ - operários os que, trabalhadores de tal categoria e residentes nesta cidade, contribuírem mensalmente com a quantia de $1 \$ 500$ e pagarem a joia de $5 \$ 000$.

a) no seu primeiro ano de existência a Sociedade não cobrará dos seus 
novos sócios a taxa de joia.

$\S 3^{\circ}$ - beneméritos os que, sendo efetivos ou operários, prestarem excepcionais serviços à Sociedade ou fizerem donativos de 1:000 $\$ 000$, pelo menos.

$\S 4^{\circ}$ - correspondentes os que, cidadãos de reconhecido valor e residentes noutras cidades, puderem prestar ou prestarem reais serviços à Sociedade e forem por ela eleitos.

Art. $4^{\circ}$ - Os sócios beneméritos e os correspondentes deverão auxiliar a Biblioteca com a oferta de livros, jornais e revistas ou de qualquer outra forma (RFS, n. 25, out. 1933, p. 14).13

Assim como os direitos e deveres eram distintos conforme as categorias descritas acima, a admissão dos mesmos à Sociedade também sofria diferença, como mostra os art. $5^{\circ}$ ao $8^{\circ}$, que apresentam com detalhes os passos para a admissão dos diferentes tipos de sócios, reforçando assim tratar-se a Sociedade de uma elite econômica e cultural, perfeitamente hierarquizada, organizada com o objetivo de edificar a Biblioteca Pública de Campo Grande como sendo um espaço de contribuição para a elevação cultural e moral da população, tendo como modelo os grandes centros, como a capital federal.

No que diz respeito ao financiamento da Biblioteca, a Sociedade da Biblioteca de Campo Grande se beneficia do estreito vínculo com a RFS, que conclama, de maneira diferenciada, a sociedade letrada a colaborar com a manutenção da Biblioteca, como no artigo Variações sobre o livro, de Menotti del Picchia, em que ele afirma:

Deixe de comprar quatro maços de cigarro. Fará um grande presente à sua saúde. Economizará 4 \$0oo. Com esse dinheiro comprará um livro. Fará um grande presente a seu espírito [...]. Que pode haver melhor que um livro? Somente uma biblioteca (RFS, n. 25, out. 1933, p. 12).

\footnotetext{
${ }^{13}$ A partir do art. $9^{\circ}$, são citados especificamente os deveres dos sócios, dentre eles " $§ 5^{\circ}$ - pagar as respectivas mensalidades adiantadamente". No art. 10, dos direitos dos sócios, o benemérito pode optar em não pagar a mensalidade: " $\$ 7^{\circ}$ - eximir-se ad-libitum de mensalidades, quando sócio benemérito" (RFS, n. 25, out. 1933, p. 14).
} 
Anos mais tarde, a Revista Folha da Serra mantém em suas páginas a campanha para aumentar o número de sócios, o apelo consiste em um

[...] pedido de auxílio, de ajuda, principalmente a todos aqueles que, orgulhosamente, blasonam o progresso e a grandeza da entusiástica cidade vermelha [...] auxilia-la dando-lhe alguns livros, coleção de jornais e revistas velhas, documentos antigos, etc., e inscrevendo-se entre os seus sócios (RFS, n. 40, ago. 1936, p. 82, grifo no original).

Ainda a respeito do financiamento da Biblioteca, além das mensalidades dos associados, "desde a sua fundação vem a Sociedade recebendo subvenção da Prefeitura e, em 1934, do Estado. Este ano [1936] o Dr. A. L. Boaventura, prefeito, aumentou o auxílio para 250\$ mensais", o auxílio antes era de 150\$: "Estamos atualmente lutando para conseguirmos uma ajuda do Estado" (RFS, n. 40, ago. 1936, p. 83).

No tocante ao acervo da Biblioteca, seu diretor esclarece que foi levantado por meio de uma "grande coleta pública" entre "todos os que sabem ler, nesta terra". A coleta foi feita "de porta em porta, na qual conseguimos reunir 800 volumes". Também foi feita a aquisição "pedindo livros continuamente [...], só assim nos foi possível nestes três anos e meio de existência, catalogar 2.700 volumes, que em breve subirão a 3.200, pois em nossa recente viagem a Cuiabá e Corumbá, trouxemos mais ou menos 500 volumes já em via de catalogação" (RFS, n. 40, ago. 1936, p. 82). Tal informação nos permite evidenciar a escassez de recursos para a compra de livros, tratando-se, o acervo da Biblioteca Pública de Campo Grande, grande parte, de doações e em situações diversas.

Cabe destacar a escassez de produção de livros no país e a dificuldade de distribuição nesse período, em especial, no estado de Mato Grosso. Na obra $O$ livro no Brasil (HALLEWELL, 2005, p. 610), o autor afirma que a distribuição de livros "pelo enorme território brasileiro é, inevitavelmente, demorada e dispendiosa". Sobre os pontos de venda de livros nos estados em 1981, o autor informa que o estado de Mato Grosso contava com dois pontos, e Mato Grosso do 
Sul, com quatro.

Do acervo da Biblioteca Pública de Campo Grande, destacava-se as seguintes obras:

História Universal, Onken, 1929, 46 volumes; Do Int. De Obras Célebres, 24 vols; Enciclopédia dic. Internacional, 20 vols; Coleção brasiliana [...] 65 vols; [...] Língua Portuguesa 1 a [...]; Livros da Revolução [...] 48 vols; História de Portugal, Schifflers, 5 vols; Guerra da Tríplice Aliança, T. Fragoso, 5 vols; Obras completas de Machado de Assis, Humberto de Campos, etc. [...] Publicações da [...] missão Rondon e da Expedição Roosevelt, [...] formando uma coleção das mais completas faltando apenas 2 [...] que estão esgotados no dizer do Cel. [...] de Medeiros, da Inspetoria Especial de Fronteiras, do Rio (RFS, n. 40, ago. 1936, p. 82).

A ênfase é dada às obras volumosas, em consonância com a valorização das enciclopédias, e a crença do conhecimento universal à disposição do homem. Nesse sentido, as bibliotecas apresentam-se como edifícios destinados ao armazenamento e consulta pública das obras clássicas.

Cabe mencionar ainda, sobre o acervo da Biblioteca Pública de Campo Grande, a seção “ 'Augusto Leverger', destinada às obras de Mato Grosso”, objetivando tornar-se um "centro de estudos e de propaganda das coisas e da vida do Estado", dando-lhe visibilidade, como rezava o Estatuto (RFS, n. 25, out. 1933 , p. 14). É importante destacar, como visto no Estatuto, que os objetivos da Sociedade da Biblioteca de Campo Grande vão ao encontro das necessidades sociais e do contexto em que está inserida, aliando-se aos interesses anunciados pela RFS, de contribuir para divulgar essa região do país, uma vez que a Revista "promete tudo fazer em bem servir os seus leitores, a par de um trabalho consciencioso de propaganda do nosso torrão natal, tão mal conhecido fora das nossas fronteiras" (RFS, n. 2, nov. 1931, p. 22).

Para além das obras de referência, enciclopédias e dicionários, também compõe o acervo da Biblioteca os periódicos, como jornais e revistas, como parte do acervo disponível para a consulta. Nesse sentido, há chamadas para a doação 
de "coleção de jornais e revistas velhas", além de anúncios como este: "Você gasta muito com jornais? Economize seu dinheiro, inscreva-se entre os sócios da Biblioteca de Campo Grande. Mensalidade: 3 \$ooo. Aberta diariamente das 19 às 22 horas" (RFS, n. 39, ago. 1935, p. 49). Esta propaganda confirma a presença dos impressos como parte do acervo da Biblioteca.

Outro dado presente na RFS diz respeito ao horário de funcionamento da Biblioteca. Além da afirmação de Lobivar de Matos, de que a biblioteca se encontrava aberta "à noite", esta é a única menção ao período de abertura. O Estatuto da Sociedade da Biblioteca menciona apenas no capítulo VIII Do patrimônio e da Biblioteca, no art. 45, que "A Biblioteca funcionará diariamente, conforme o horário aprovado anualmente pela diretoria”.

A Figura 1 ilustra a estrutura interna da Biblioteca Pública de Campo Grande, a disposição dos móveis e organização dos livros, permitindo visualizar $o$ arranjo espacial do edifício.

Figura 1 - Aspecto do interior da Biblioteca Pública em 1936.
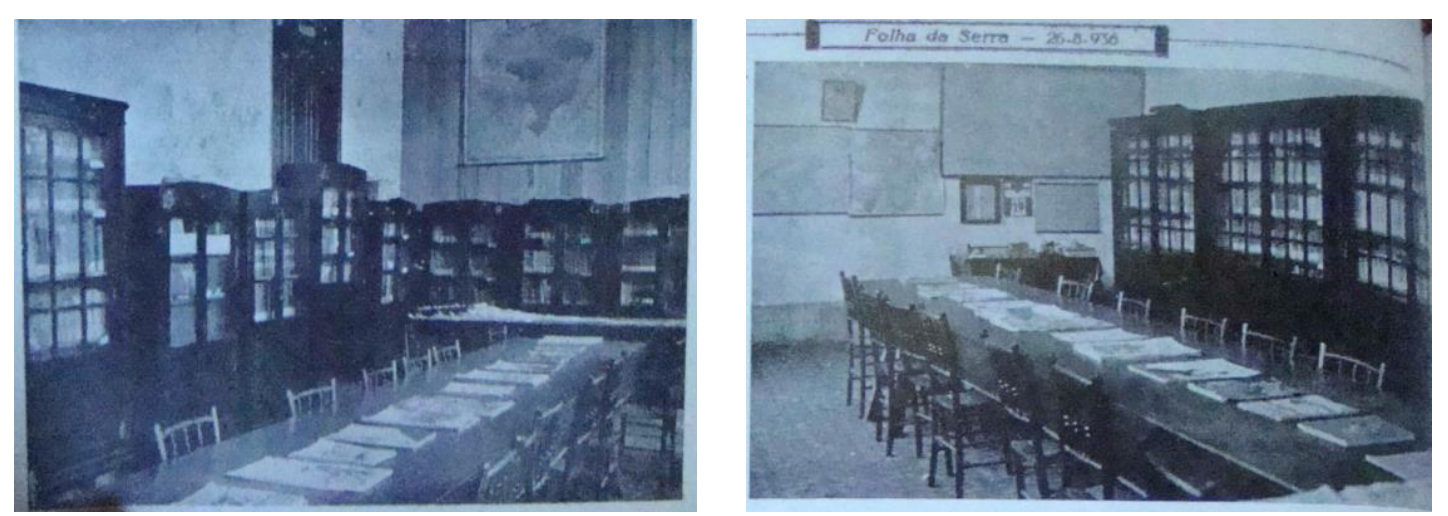

Fonte: Revista Folha da Serra, n. 40, ago. 1936, p. 82.

Nessa mesma edição que expõe as fotografias das instalações da Biblioteca, seu diretor informa: 


\begin{abstract}
Estamos, presentemente, empenhados na organização do "Arquivo Público" (para a documentação da história de Mato Grosso e, especialmente de Campo Grande) e da "Seção Augusto Leverger", onde se encontrarão todas as obras publicadas no e sobre o Estado (RFS, n. 40, ago. 1936, p. 83).
\end{abstract}

Essa afirmação demonstra que nem todos os objetivos previstos no Estatuto foram cumpridos, passados três anos e meio de existência da Biblioteca.

Dentre os eventos realizados pela Sociedade, estavam "20 palestras sobre a criança, feitas por médicos e professores”. Muitas das conferências e palestras organizadas pela Sociedade da Biblioteca de Campo Grande serviram para propagar "noções de higiene", como parte dos objetivos estabelecidos pela instituição ("trabalhar junto aos colegiais e ao povo, ensinando-lhes noções de higiene") (RFS, n. 25, out. 1933, p. 14), especialmente tendo a biblioteca um médico como presidente.

\begin{abstract}
A SOCIEDADE DA BIBLIOTECA DE CAMPO GRANDE em fins do ano passado [1935], de 15-10 a 17-12 promoveu uma série de Palestras sobre a criança, das quais se incumbiram médicos e professores. Todas as segundas feiras daquele período, o salão da Biblioteca acolhia numerosa assistência que lá acorria afim de ouvir conselhos sobre higiene e pedagogia caseiras. A série dessas palestras foi aberta pelo Bacharel Estácio C. Trindade, que discorreu sobre a educação de um modo geral (RFS, ns. 37 e 38, jan. e fev. 1935, p. 7, grifo no original).
\end{abstract}

Destaca-se a preocupação com a higiene, advinda do início do século XIX no Brasil, com a vinda da família real e o aumento gradativo da população e das epidemias, exigindo uma intervenção higiênico-sanitária, com as teorias eugênicas e novas estratégias de controle do corpo pelas políticas públicas. A higiene tornou-se parte fundamental da medicina, passando a impor normas e condutas acerca da alimentação correta, da moradia, da forma adequada de se vestir, de dormir etc., quando se enfatizou a preservação e os cuidados com a criança por parte dos médicos e das famílias. Na década de 1930, Getúlio Vargas fez do higienismo seu ponto forte de governo no que se referia à saúde e à 
educação de uma nova nação. Nesse sentido, os problemas de desnutrição e mortalidade infantil não eram enfatizados na imprensa, mas sim, supostas soluções para todos os problemas que se apresentavam na sociedade, como evidenciou Teixeira (2011) e se pode constatar nas páginas da RFS.

A primeira da série de palestras no ano de 1935 teve por título "Educar" (RFS, ns. 37 e 38, jan. e fev. 1935, p. 7); a segunda, "Como iniciar a educação do bebê" com o subtítulo, "Brinquedos e hábitos do primeiro ano. Nocividade e utilidade deste", proferida pelo Dr. Peri Alves Campos, diretor da Biblioteca "na série de palestras sobre a criança, promovida pela Sociedade da Biblioteca de C. Grande", naquele ano (RFS, n. 39, ago. 1935, p. 11-13 e 57).

Ainda em 1935 a Sociedade da Biblioteca de Campo Grande promoveu o Concurso de robustez do bebê, no qual foram inscritos um total de 20 bebês, compareceram 17, os quais foram avaliados por uma comissão médica convidada especialmente para efetuar o concurso, que configura, segundo Bel. Estácio, "As palestras que a Diretoria da Biblioteca de Campo Grande houve por bem organizar e executar, desta noite ao dia 17 de dezembro próximo, a encerrar-se com a apoteose ao bebê mais robusto, em concurso original para nós" (RFS, ns. 37 e 38, jan. e fev. 1935, p. 7, grifo nosso). O concurso de bebês robustos, uma prática já conhecida nos grandes centros, foi apresentado como um evento inédito em Campo Grande, em consonância com a tentativa de se aproximar das atividades previstas na capital federal, que reforçam as políticas sociais da infância e as práticas higienistas em voga desde o final do século XIX, como o Congresso Brasileiro de Proteção à Infância, em 1933, no Rio de Janeiro, e a Diretoria de Proteção à Maternidade e a Infância, interligada ao Ministério da Educação e Saúde Pública, criada em 1934. Como afirma Kulhmann Jr. (2002, p. 465): "Os cuidados com a infância tornam-se um aspecto a ser considerado nesse modelo de nação moderna, com suas políticas sociais e instituições”.

Entre as atividades sociais e educativas promovidas pela Biblioteca Pública, no ano de 1936 a RFS destaca a existência de um "curso de inglês, privativo dos sócios", como forma de bonificação e distinção dos membros 
associados, ao mesmo tempo que institui, como parte de suas ações, a criação da "Escola primária Augusto Leverger, destinada exclusivamente à alfabetização de crianças pobres, fornecendo livros e material escolar". A escola, como se anuncia, "é subvencionada pela Prefeitura com 100\$, de copioso material técnico didático" (RFS, n. 40, ago. 1936, p. 83). Trata-se, ao que parece, de novas estratégias para ampliar e qualificar o número de leitores na região.

Considerando que a Revista Folha da Serra só publicou dois números em 1937, ano de implantação do Estado Novo e não circulou nos anos de 1938 e 1939, voltando a circular em julho de $1940^{14}$, neste ano a Revista divulga com destaque no Editorial, dentre as atividades propostas pela Biblioteca Pública de Campo Grande, a realização de um concurso de História de Mato Grosso:

\begin{abstract}
$1^{\circ}$ Concurso de História de Mato Grosso, idealizado e patrocinado pela nossa Biblioteca Municipal e pela Sociedade Miguel Couto, dos amigos do Estudante, e no qual tomaram parte aproximadamente 60 dos nossos Ginasianos, constituiu uma prova cívica de elevada significação, como sendo uma pugna intelectual que pela primeira vez se levou avante em terras mato-grossenses. Seu significado, enquadrado amplamente no espírito salutar e reformador do governo Vargas - de linhas mestras vigorosas - se amplia e reforça ao se considerar que, em Mato Grosso, o estudante completa seus estudos primários, normal e secundário sem jamais aprender, se quer, uma página de sua história, relegada ao maior do menosprezo (RFS, n. 45, set. 1940, p. 15).15
\end{abstract}

Destacamos a ênfase da chamada do concurso como ampliador e reforçador do "espírito salutar e reformador do governo Vargas", possivelmente pela sua ênfase na integralização e nacionalização do país, que buscava, já em 1936, com a criação do Instituto Brasileiro de Geografia e Estatística (IBGE) do sistema estatístico do país, um novo conhecimento do país, de sua cultura, sua geografia e seus habitantes.

\footnotetext{
14 Sobre a produção e circulação da Revista Folha da Serra, Cf. Passone Rodrigues (2017).

${ }_{15}$ Em nota, "Retificações", o número seguinte corrige que o Concurso foi idealizado pela "Sociedade Miguel Couto dos Amigos do Estudante" (RFS, n. 48, dez. 1940, p. 17).
} 
Observamos ainda que houve uma mudança no nome da Biblioteca, que acrescentou "municipal" em sua definição, nas reportagens apresentas no ano de 1940 na RFS. Não há menção sobre a mudança de administração nas páginas da Revista, mas sabemos que ela foi doada à prefeitura municipal de Campo Grande, segundo consta hoje em sua página virtual. ${ }^{16}$

A reportagem dá destaque ao entusiasmo dos estudantes com o concurso, que passaram a frequentar com maior intensidade a Biblioteca Pública, cumprindo assim, ao que tudo indica, com o objetivo do concurso:

A quem frequentasse a Biblioteca Pública na última quinzena de agosto e na primeira semana do presente mês seria dado ver, com que entusiasmo, meninos e meninas, moças e rapazes se entregavam ao manuseio dos livros e monografia dos nossos melhores autores. Até a 'Revista do Instituto Histórico de Mato Grosso', excelente mas de circulação nula e absolutamente ignorada, desceu das prateleiras e teve suas folhas ventiladas... [...] Diante da lição, que ponderações terão as nossas entidades máximas da cultura - a Academia Mato-grossense de Letras e Instituto Histórico - as quais deveriam caber, em suas longas existências, gestos que as tornassem de vida concreta e palpável? Sentindo a atividade e a existência de historiadores os jovens aprenderiam a melhor amar e respeitar a história [...] (RFS, n. 45, set. 1940, p. 15).

Dois meses depois, em novembro de 1940, a Revista Folha da Serra estampa em sua capa (Fig. 2) a vencedora do primeiro concurso de história de Mato Grosso, com a seguinte legenda:

A jovem e talentosa campo-grandense Senhorita Virginia Belico, que acaba de terminar com brilhantismo o Curso de Normalista pela Escola Normal do Estado e que obteve o primeiro lugar no Concurso de História de Mato Grosso, instituído pela Biblioteca Pública Municipal desta cidade (RFS, n. 47, nov. 1940, capa).

${ }_{16}$ Disponível em: http://www.pmcg.ms.gov.br/fundac/canaisTexto?id_can=6883. Acesso em: 07 out. 2016. 
Figura 2 - Senhorita Virginia Belico, vencedora do $1^{\circ}$ Concurso de História de Mato Grosso.

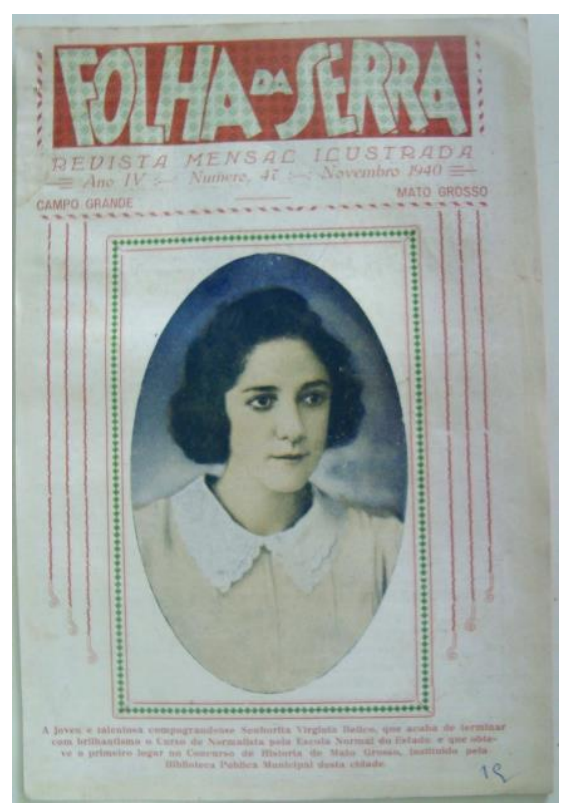

Fonte: Revista Folha da Serra, n. 47, nov. 1940, capa.

Trata-se da última reportagem que faz menção à Biblioteca Pública de Campo Grande, aqui municipalizada, e do penúltimo número da RFS, que finaliza sua circulação no mês seguinte, com 48 números, o que nos permite afirmar que o período de circulação da RFS, durante a década de 1930 esteve a todo o tempo estreitamente vinculado às estratégias de criação e funcionamento da Biblioteca Pública de Campo Grande, confirmando a afirmação de Chartier (1990, p. 138) sobre o poder dos impressos, que prescrevem comportamentos, estabelecem novos hábitos, novos valores, e neste caso, cria uma instituição com o intuito de ampliar e qualificar o número de leitores em Mato Grosso.

Por fim, observamos mais uma vez a presença da mulher no discurso da RFS vinculado a Biblioteca Pública de Campo Grande, vencedora de um concurso sobre a história do Estado. No primeiro momento destacou-se sua presença entre o público na celebração inaugural; no segundo momento enfatizou-se o objetivo de facilitar o estudo das ciências, letras e artes "às brasileiras". Outro esforço seria a realização de um evento em 1933 com a presença da "ilustre escritora" Maria Sabina, "uma das expressões mais altas da poesia feminina indígena", 
patrocinado pela Sociedade da Biblioteca de Campo Grande e pela Revista Folha da Serra (RFS, n. 22, jul. 1933, p. 2) ${ }^{17}$. Tais chamadas parecem tratar-se de estratégias por parte dos membros dirigentes da RFS para conquistar o público feminino, que tinha espaço garantido entre as imagens e textos que compunham o periódico, inclusive como autoras.

\section{À GUISA DE CONCLUSÃO}

Assim como um artesão ao tecer um bordado, o trabalhar se processa na parte superior como que um dançar de cores e formas, mas no verso, há um emaranhado confuso de linhas e sentidos, mas sem o verso não há arte, é justamente o conjunto que dá forma ao final do processo, como expõe Ginzburg (2007). De modo semelhante, ao analisar a criação e funcionamento da Biblioteca Pública de Campo Grande nos anos 1930 a partir das páginas da RFS, a narrativa se mostrou ora pela frente ora pelo verso, coerências e contradições formaram parte da história dessa instituição que ora apresentamos.

A primeira costura girava em torno da relação entre a Biblioteca e a RFS. A criação da Biblioteca Pública de Campo Grande escondia em seu verso muitas linhas soltas que ao serem investigadas, revelaram um trabalho minucioso e bem arquitetado. Houve participação do poder público na criação da Biblioteca, apesar da iniciativa particular, por parte da Sociedade da Biblioteca de Campo Grande, criada, por sua vez, por iniciativa do grupo dirigente da RFS. A união de interesses que levou o poder público e os editores da Revista a se reunirem em prol da Biblioteca é a essência da tessitura.

Ancorados aos propósitos nacionais de busca da modernidade, a Biblioteca e o incentivo à leitura, dentre outras representações perpassadas na época, simbolizavam o modelo do novo cidadão, intelectual e culto que Mato Grosso almejava. Para os administradores políticos de Campo Grande, a

\footnotetext{
${ }^{17}$ No entanto, a RFS não mencionou a realização de tal evento.
} 
Biblioteca oportunizaria ascensão, como um passo a mais na busca da urbanização. Já a RFS, necessitava ampliar o rol de assinantes leitores do periódico para sobreviver no mercado. Portanto, nada era inócuo e inocente, os jogos de interesses cirandavam por todos os lados.

Fica evidente a detenção de poder em relação as tomadas de decisões frente a Biblioteca Pública de Campo Grande, uma vez que os eventos idealizados, projetos e ações efetivadas, passavam pelas mãos de um grupo seleto de membros da Sociedade, um grupo que compunha a elite intelectual daquele reduto, agindo de forma estratégica na construção de um novo público leitor, com sutis estratégias para inclusão do público feminino. O Estatuto da Sociedade da Biblioteca registra um alto teor hierárquico e seletivo na escolha de seus sócios. Porém, apesar de marcar a segregação entre uma elite econômica e cultural, as atividades realizadas por essa instituição buscavam a ampliação e qualificação do número de leitores, além de propor, como essência, a democratização do acesso ao conhecimento e à informação, como símbolo do progresso e da modernidade em voga nos anos 1930.

Ao analisar as constantes chamadas da RFS, em resposta ao baixo nível de associados à Biblioteca, após sua instalação, prevalecia vozes de valorização da biblioteca, incentivo do hábito da leitura, completude do papel da escola, enfim, discursos intencionais na busca de sensibilizar o público e criar novos sentidos, hábitos e valores em torno da recém-criada instituição, ao mesmo tempo em que os discursos em prol da Biblioteca evidenciavam a escassez de interesse da população por aquele "imprescindível centro de culturas", ao denunciar que "a nossa gente tem horror aos livros".

À primeira vista tudo se mostrou impecável, sem nós, sem curvas, entretanto, ao olhar os arremates no verso, algo estava escapando aqui e acolá, em meio ao emaranhado de linhas soltas que foram sendo criadas ao analisar a fonte, sendo possível, gradativamente entender e ligar alguns pontos, tecendo algumas formas, alguns sentidos, mas deixando outros ainda por serem arrematados. 


\section{REFERÊNCIAS}

ARAUJO, Susylene Dias de. A vida e a obra de Lobivar Matos: o modernista (des)conhecido. 2009. 270 f. Tese (Doutorado em Letras) Universidade Estadual de Londrina, Londrina/PR. 2009.

BATISTA, Antonio Augusto; GALVÃO, Ana Maria de Oliveira. Leitura: práticas, impressos, letramentos. Belo Horizonte: Autêntica, 1999.

BICCAS, Maurilane de S. O impresso como estratégia de formação: Revista de Ensino de Minas Gerais (1925-1940). Belo Horizonte, MG: Argvmentvm, 2008.

BRITO, Silvia Helena Andrade. Educação e sociedade na fronteira oeste do Brasil: Corumbá (1930-1954). 2001. Tese (Doutorado em Educação) Faculdade de Educação, Universidade Estadual de Campinas/Unicamp, Campinas/SP, 2001.

CALDAS, Aulete. Dicionário escolar de língua portuguesa. Org. Paulo Geiger. Rio de Janeiro: Lexikon, 2012. 1072 p.

CATANI, Denice Bárbara; BASTOS, Maria Helena Câmara (org.). Educação em Revista. A imprensa periódica e a história da educação. São Paulo: Escrituras Editora, 2002.

CERTEAU, Michel de. A invenção do cotidiano: 1. Artes de fazer. Petrópolis, RJ: Vozes, 1994.

CESARINO, Maria Augusta da Nóbrega. Biblioteca Pública Estadual Luiz de Bessa: 50 anos de cultura. Belo Horizonte: Secretaria de Estado da Cultura de Minas Gerais, Superintendência de Bibliotecas Públicas, 2006.

CHARTIER, Roger. A história cultural: entre práticas e representações. Rio de Janeiro: Difel; Bertrand Brasil, 1990.

CHARTIER, Roger. Práticas da Leitura. São Paulo: Estação Liberdade, 1996.

CHAUÍ, Marilena. Brasil - mito fundador e sociedade autoritária. São Paulo: Perseu Abramo, 2000.

FARIA FILHO, Luciano Mendes de. O jornal e outras fontes para a história da educação mineira do século XIX: uma introdução. In: ARAUJO, José Carlos Souza; GATTI JÚNIOR, Décio (org.). Novos temas em história da educação brasileira: instituições escolares e educação na imprensa. 
Campinas: Autores Associados, 2002. p. 133-150.

GALETTI, Lylia da Silva Guedes. Nos confỉns da civilização: sertão, fronteira e identidade nas representações sobre Mato Grosso. 2000. $385 \mathrm{f}$. Tese (Doutorado em História) - Faculdade de Filosofia, Letras e Ciências Humanas/FFLH, Universidade de São Paulo/USP, São Paulo, 2000.

GINZBURG, Carlo. O fio e os rastros: verdadeiro, falso, fictício. São Paulo: Companhia das Letras, 2007.

HALLEWELL, Laurence. O livro no Brasil: sua história. São Paulo: Edusp, 2005 .

LUCA, Tania Regina de. História dos, nos e por meio dos periódicos: trajetórias e perspectivas analíticas. In: PINSKY, Carla Bassanezi (org.). Fontes

históricas. São Paulo: Contexto, 2005.

PAIVA, Marília de Abreu Martins de. Bibliotecas públicas: políticas do Estado brasileiro de 1990 a 2006. 2008. 140 f. Dissertação (Mestrado em Ciência da Informação) - Escola de Ciência da Informação, Universidade Federal de Minas Gerais, Belo Horizonte/MG, 2008.

QUEIROZ, Paulo R. Cimó. Uma ferrovia entre dois mundos: a E. F. Noroeste do Brasil na $1^{\mathrm{a}}$. metade do século XX. Bauru: Edusc; Campo Grande: Ed. UFMS, 2004. 526 p.

RODRIGUES, Eglem de Oliveira Passone. A Revista Mensal Ilustrada da Folha da Serra e suas dimensões educativas (sul de Mato Grosso, 1931-1940). 2017. 180 f. Dissertação (Mestrado em Educação) - Faculdade de Educação, Universidade Federal da Grande Dourados, Dourados/MS, 2017.

TEIXEIRA, Clara. Cinejornal Brasileiro: eugenia adaptada no Estado Novo. Revista Científica FAP, Curitiba, v. 8, p. 163-180, jul./dez. 2011.

\section{FONTES}

RFS. Revista Mensal Ilustrada Folha da Serra, Campo Grande, n. 01, out. 1931. Arquivo Público de Campo Grande (Arca), Campo Grande, Mato Grosso do Sul.

RFS. Revista Mensal Ilustrada Folha da Serra, Campo Grande, n. 02, nov. 1931. Arquivo Público de Campo Grande (Arca), Campo Grande, Mato Grosso 
do Sul.

RFS. Revista Mensal Ilustrada Folha da Serra, Campo Grande, n. 05, fev. 1932. Arquivo Público de Campo Grande (Arca), Campo Grande, Mato Grosso do Sul.

RFS. Revista Mensal Ilustrada Folha da Serra, Campo Grande, n. 16, jan. 1933. Biblioteca Central da UFGD, Acervo professor José Pereira Lins, Dourados, Mato Grosso do Sul.

RFS. Revista Mensal Ilustrada Folha da Serra, Campo Grande, n. 18, mar. 1933. Biblioteca Central da UFGD, Acervo professor José Pereira Lins, Dourados, Mato Grosso do Sul.

RFS. Revista Mensal Ilustrada Folha da Serra, Campo Grande, n. 22, jul. 1933. Biblioteca Central da UFGD, Acervo professor José Pereira Lins, Dourados, Mato Grosso do Sul.

RFS. Revista Mensal Ilustrada Folha da Serra, Campo Grande, n. 23, ago. 1933. Arquivo Público de Mato Grosso (APMT), Cuiabá.

RFS. Revista Mensal Ilustrada Folha da Serra, Campo Grande, n. 24, set. 1933. Biblioteca Central da UFGD, Acervo professor José Pereira Lins, Dourados, Mato Grosso do Sul.

RFS. Revista Mensal Ilustrada Folha da Serra, Campo Grande, n. 25, out. 1933. Biblioteca Central da UFGD, Acervo professor José Pereira Lins, Dourados, Mato Grosso do Sul.

RFS. Revista Mensal Ilustrada Folha da Serra, Campo Grande, n. 26, nov. 1933. Biblioteca Central da UFGD, Acervo professor José Pereira Lins, Dourados, Mato Grosso do Sul.

RFS. Revista Mensal Ilustrada Folha da Serra, Campo Grande, n. 30, mar. 1934. Biblioteca Central da UFGD, Acervo professor José Pereira Lins, Dourados, Mato Grosso do Sul.

RFS. Revista Mensal Ilustrada Folha da Serra, Campo Grande, n. 39, ago. 1935. Biblioteca Central da UFGD, Acervo professor José Pereira Lins.

Dourados, Mato Grosso do Sul.

RFS. Revista Mensal Ilustrada Folha da Serra, Campo Grande, n. 40, ago. 1936. Arquivo Público de Campo Grande (Arca), Campo Grande, Mato Grosso do Sul. 
RFS. Revista Mensal Ilustrada Folha da Serra, Campo Grande, n. 45, set. 1940. Biblioteca Central da UFGD, Acervo professor José Pereira Lins, Dourados, Mato Grosso do Sul.

RFS. Revista Mensal Ilustrada Folha da Serra, Campo Grande, n. 46, out. 1940. Biblioteca Central da UFGD, Acervo professor José Pereira Lins, Dourados, Mato Grosso do Sul.

RFS. Revista Mensal Ilustrada Folha da Serra, Campo Grande, n. 47, nov. 1940. Biblioteca Central da UFGD, Acervo professor José Pereira Lins, Dourados, Mato Grosso do Sul.

RFS. Revista Mensal Ilustrada Folha da Serra, Campo Grande, n. 48, dez. 1940. Biblioteca Central da UFGD, Acervo professor José Pereira Lins, Dourados, Mato Grosso do Sul.

RFS. Revista Mensal Ilustrada Folha da Serra, Campo Grande, ns. 11 e 12, ago. e set. 1932. Biblioteca Central da UFGD, Acervo professor José Pereira Lins, Dourados, Mato Grosso do Sul.

RFS. Revista Mensal Ilustrada Folha da Serra, Campo Grande, ns. 13, 14 e 15, out., nov. e dez. 1932. Biblioteca Central da UFGD, Acervo professor José Pereira Lins, Dourados, Mato Grosso do Sul.

RFS. Revista Mensal Ilustrada Folha da Serra, Campo Grande, ns. 28 e 29, jan. e fev. 1934. Biblioteca Central da UFGD, Acervo professor José Pereira Lins, Dourados, Mato Grosso do Sul.

RFS. Revista Mensal Ilustrada Folha da Serra, Campo Grande, ns. 37 e 38, jan. e fev. 1935. Biblioteca Central da UFGD, Acervo professor José Pereira Lins, Dourados, Mato Grosso do Sul. 
KÊNIA HILDA MOREIRA é graduada em História pela Universidade Federal de Goiás (UFG) (2002), mestre (2006) e doutora (2011) pela Universidade Estadual Paulista (Unesp), com estágio de doutorado na Universidade de Salamanca (2009-2010). Professora no Programa de Pós-Graduação em Educação (mestrado e doutorado) e na Faculdade de Educação da Universidade Federal da Grande Dourados (UFGD). Vice-líder do Grupo de Estudos e Pesquisas em História da Educação, Memória e Sociedade (Gephemes).

E-mail: keniamoreira@ufgd.edu.br

(i) http://orcid.org/0000-0002-0265-4783

Recebido em: 26 de fevereiro de 2018

Aprovado em: 12 de janeiro de 2019 